\title{
Research Report on MTCSOL Dissertation Topics in the Last Decade $^{1}$
}

\author{
ZHANG Jie, ZHANG Hou-xing, ZHANG Yue, LIAO Jin-yu, REN Xiao-fei \\ Jiangsu University, Zhenjiang, China
}

\begin{abstract}
Dissertation is one of the most important indicators to evaluate the training quality of postgraduate students. As the first step of writing dissertations, topic selection directly influences the dissertation quality. By utilizing the intelligent retrieval system of the National Science and Technology Library (NSTL), we have selected MTCSOL (Master of Teaching Chinese to Speakers of Other Languages) dissertation topics during the last 10 years, divided them into four stages and statistically analyzed the general tendency and crucial problems in these dissertations. MTCSOL dissertations have increased greatly in quantity and become more diversified and multidisciplinary. However, they are still too concentrated on similar topics with narrow scopes; and researches lack of creativity, pioneering spirits and practicality. It concludes that MTCSOL students should expand their research scopes and improve the quality of their dissertations with the historic mission of international Chinese language teaching to support the Belt and Road Initiative and build a harmonious community with shared future for humanity in the new era always in their minds.
\end{abstract}

Keywords: MTCSOL, dissertation, topic selection

\section{Quantity Analysis of MTCSOL Dissertations}

This paper, retrieving the key word “对外汉语 (duì waì hàn yǔ, Chinese as a foreign language)” in the National Science and Technology Library (NSTL), with the awarding years of master degrees as the filtering criteria, has selected 6,641 MTCSOL (Master of Teaching Chinese to Speakers of Other Languages) dissertations (2007-2017). The numbers of dissertations for each year are illustrated as follows:

ZHANG Jie, lecturer, School of Liberal Arts \& Language and Culture Center, Jiangsu University, Zhenjiang, China.

ZHANG Hou-xing, TCSOL postgraduate student, School of Liberal Arts \& Language and Culture Center, Jiangsu University, Zhenjiang, China.

ZHANG Yue, TCSOL postgraduate student, School of Liberal Arts \& Language and Culture Center, Jiangsu University, Zhenjiang, China.

LIAO Jin-yu, TCSOL postgraduate student, School of Liberal Arts \& Language and Culture Center, Jiangsu University, Zhenjiang, China.

REN Xiao-fei, Doctor, Professor, School of Liberal Arts \& Language and Culture Center, Jiangsu University, Zhenjiang, China.

${ }^{1}$ This study is funded by the key national social science foundation project "Overseas Dissemination and Influence of Ancient Chinese Classic Primers” (17AZS012) and the TCSOL Professional Degree Postgraduate Education Research Project 2017: Research on the Intercultural Communication Competence Cultivation System for MTCSOL (HGJ201713) and 2018 Jiangsu Province Postgraduate Practice and Innovation Plan (SJCX18_0719): The Dissemination and Influence of Confucius's View of Human Nature in Singapore. 


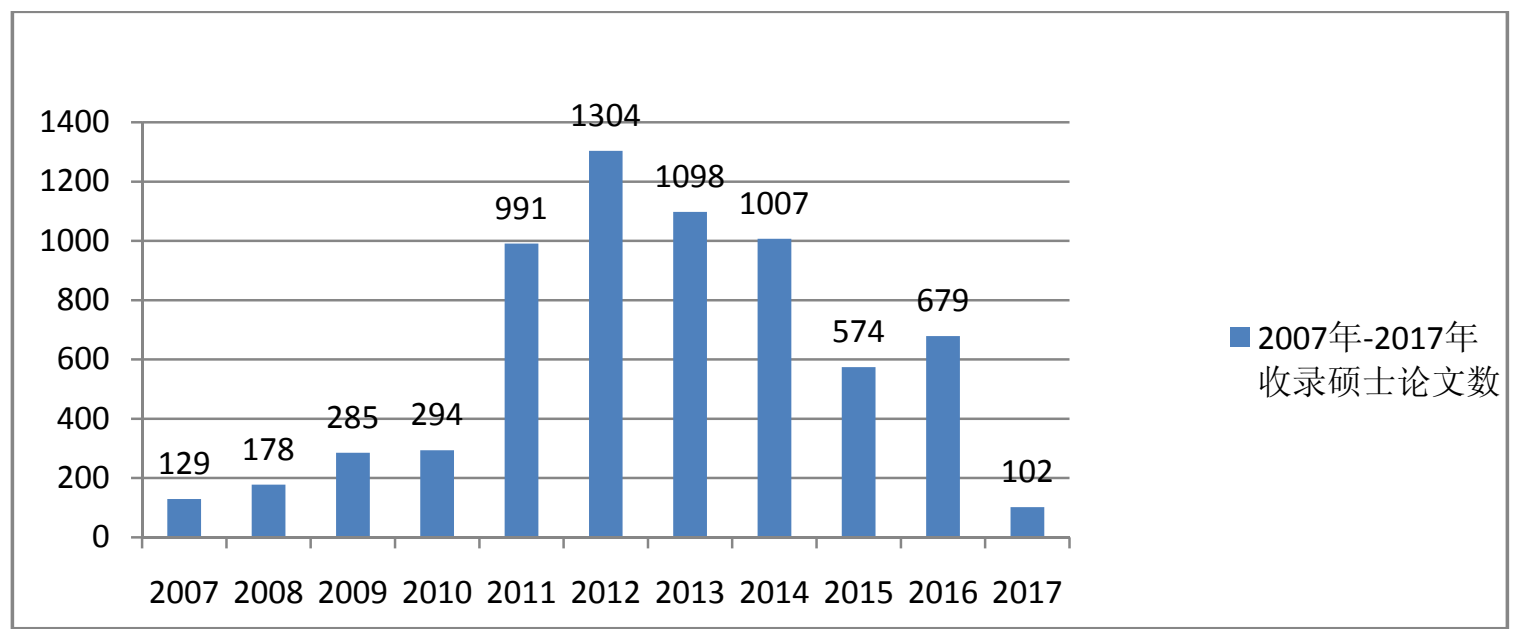

Figure 1. Numbers of MTCSOL dissertations in the last decade (courtesy of National Science and Technology Library).

It can be seen from Figure 1 that, from 2007 to 2017, the number of MTCSOL dissertations collected has been clearly on the increase, with an average of 604 dissertations per year and 6,641 dissertations in total, which shows that MTCSOL education has developed greatly in the last 10 years. Especially since 2011, with the number of dissertations multiplied, great progress has been made in MTCSOL education.

There are several reasons for the substantial boost in MTCSOL dissertations:

1. Since the foundation of the 1st Confucius Institute in Seoul in 2004, as the most regular and primary channel for Chinese teaching, Confucius Institute has prospered vigorously. By December 2017, 525 Confucius Institutes and 1,113 Confucius Classrooms have been set up in 146 countries or regions across the world. For the last 10 years, more than 200,000 culture activities, with an audience of over 100 million, have been sponsored by Confucius Institutes or Confucius Classrooms worldwide. As a result, the rapid development of TCSOL has created a great demand for qualified TCSOL teachers, which is still steadily on the increase.

2. MTCSOL programs are being offered in more and more colleges or universities. Since the first MTCSOL programs were offered in 24 colleges or universities in 2007, many colleges and universities have started to set up MTCSOL programs. In addition to numerous normal colleges and language colleges, a lot more comprehensive universities have been approved to cultivate masters of TCSOL. So far, there are over 100 higher educational institutions in total offering MTCSOL education.

3. MTCSOL has gradually been recognized and accepted by the public globally. The development of Internet teaching platform has diversified job opportunities in the trend of global "Chinese craze". Besides, its multi-disciplinarity has attracted students majoring in Chinese language and literature, applied linguistics, and foreign languages to study this program.

\section{Analysis of TCSOL Dissertation Topics}

In selecting MTCSOL dissertation topics, students should closely combine their knowledge with TCSOL practice to demonstrate their ability to comprehensively apply scientific theory, method and technology to solving actual TCSOL problems. TCSOL practice covers not only teaching Chinese as a second/foreign language, but also Chinese culture dissemination, intercultural communication, teacher's professional development, and so on. 
As per the training program for MTCSOL, related researches of TCSOL may be catogorized into five modules: teaching Chinese as a second language (inclusive of Chinese teaching method, Chinese teaching resources, and Chinese language test), Chinese (as a second language) acquisition, ontological features of Chinese, culture and communication (Chinese culture and intercultural communication), and quality of Chinese language teachers.

This paper, with “对外汉语 (duì waì hàn yǔ, Chinese as a foreign language)” as the key word, selected 50 most-cited dissertations since 2007 from the master dissertation database of China National Knowledge Infrastructure (CNKI) and grouped them according to the above-mentioned five modules as follows.

Table 1

Research Field Distribution of 50 Most-Cited Master Dissertations

\begin{tabular}{|c|c|c|c|c|c|}
\hline Order & \multicolumn{2}{|c|}{ Research fields } & \multicolumn{2}{|c|}{ Quantity } & Ratio \\
\hline \multirow{3}{*}{1} & \multirow{3}{*}{ Teaching Chinese as a second language } & Chinese teaching method & 17 & \multirow{3}{*}{30} & $34 \%$ \\
\hline & & Chinese teaching resources & 12 & & $24 \%$ \\
\hline & & Chinese language test & 1 & & $2 \%$ \\
\hline 2 & Chinese (as a second language) acquisition & Chinese acquisition & 3 & 3 & $6 \%$ \\
\hline 3 & Ontological features of Chinese & Ontological features of Chinese & 4 & 4 & $8 \%$ \\
\hline 4 & Quality of Chinese language teachers & Quality of teachers & 3 & 3 & $6 \%$ \\
\hline \multirow{2}{*}{5} & \multirow{2}{*}{ Culture and communication } & Intercultural communication & 7 & \multirow{2}{*}{10} & $14 \%$ \\
\hline & & Chinese culture dissemination & 3 & & $6 \%$ \\
\hline Total & \multicolumn{4}{|c|}{50} & $100 \%$ \\
\hline
\end{tabular}

It can be inferred from Table 1 that the distribution of the 50 dissertations in the five modules is: teaching Chinese as a second language $>$ culture and communication $>$ ontological features of Chinese $>$ Chinese (as a second language) acquisition = quality of Chinese language teachers. Teaching Chinese as a second language, the most important research field, takes $60 \%$, which is more than the sum of all the other topics. However, through analysis, we discovered that there exist great differences of topic selections among its three sub-fields: 17 dissertations on Chinese teaching method, 34\%; 12 dissertations on Chinese teaching resources, 24\%; and one dissertation on Chinese language test, $2 \%$. Papers on Chinese teaching method are mainly concentrated on application of certain teaching methods in teaching practice. In "Application of Task Design of TBLT to the Primary Stage of Oral TCSL", on the basis of teaching practice and other previous researches, Lv (2007) enriched and developed the task-designing principles in oral teaching of TCSOL. Following these principles, combining classroom observation and records, relying on extensively used short-term textbooks, Lv proposed 12 types of task designs, such as task listing, sorting, and categorizing, catering to the primary stage of oral teaching of TCSOL. By evaluating, analyzing, and summarizing these tasks' characteristics and problems, Lv put forward specific design thinking and practicable methods of classroom teaching for Chinese language teachers.

Ten dissertations are related to the culture and communication module, $20 \%$ of the total; and seven dissertations are related to inter-cultural communication, 14\%. In "Culture Vocabulary in TCSOL and Related Teaching Researches”, Meng (2012) investigated the status quo of researches concerning culture vocabulary from various perspectives and accentuated the necessity and importance in TCSOL and made some suggestions on how to better apply it to classroom teaching. 
Dissertations on ontological features of Chinese, Chinese (as a second language) acquisition, and quality of Chinese language teachers are relatively few, only taking $8 \%, 6 \%$, and $6 \%$ respectively.

\section{Analysis of Research Methods of MTCSOL Dissertations}

Empirical researches, based on studies of data and materials, can be categorized as quantitative research, qualitative research, and mixed research accordingly. Researches not based on systematic materials are called non-empirical researches.

In empirical researches, quantitative research is based on sample data analysis and conducted through data collecting and quantitative analysis, while qualitative research is carried out through textual description and analysis. The research method combining the above-mentioned two methods is called mixed research.

According to the above research methods, the 50 dissertations can be categorized as follows:

Table 2

Research Field Distribution of 50 Most-Cited Master Dissertations

\begin{tabular}{|c|c|c|c|}
\hline \multicolumn{2}{|c|}{ Research methods } & Quantity & Ratio \\
\hline \multirow{3}{*}{ Empirical research } & Quantitative research & 16 & $32 \%$ \\
\hline & Qualitative research & 15 & $30 \%$ \\
\hline & Mixed research & 10 & $20 \%$ \\
\hline \multicolumn{2}{|c|}{ Non-empirical research } & 9 & $18 \%$ \\
\hline \multicolumn{2}{|c|}{ Total } & 50 & $100 \%$ \\
\hline
\end{tabular}

Among them, 41 dissertations are based on empirical studies of data and materials, $82 \%$ of the total; nine dissertations are non-empirical researches, $18 \%$ of the total. In empirical researches, the number of dissertations on quantitative researches, qualitative researches, and mixed researches are 16, 15, and 9 respectively.

Due to the nature of the discipline, dissertations with quantitative research of samples are mainly non-experiment researches, adopting univariate analysis. Few dissertations are multivariate analysis. The data statistical analysis software used for this research is SPSS.

The 15 qualitative research dissertations, with data collected through literature retrieval, interview, classroom observation, and other methods, compared applications of a certain teaching method or teaching resources in classroom teaching and better described some teaching phenomena or discovered and analyzed some problems. In "Introduction of Cultural Knowledge in Teaching Chinese as a Foreign Language", by collecting and summarizing researches of TCSOL and combining classroom observation, Xu (2008) has investigated and studied this method.

The other 10 dissertations, adopting quantitative researches like questionnaire surveys and qualitative researches like classroom observation, belong to mixed researches. In "Teacher Talk in Oral Interaction in TCFL Elementary Classrooms: A Survey and Analysis”, taking teacher talk in the classroom interaction of primary TCSOL in the Overseas Education College of Xiamen University as the research object, Wang (2009) set up control groups, by means of questionnaire surveys, interviews, classroom observations, and sound recording, and carried out both quantitative and qualitative analyses of the differences of amount and forms of discourse and questions raised by teachers in teacher-student interaction between the two teaching groups. Based on these, Wang further discussed the effectiveness of teacher talk on promoting classroom interactions 
and, accordingly, pushing forward students' language acquisition and learning.

The nine non-empirical research dissertations mainly focus on classroom teaching design, such as Cao's (2010) “Teaching Design of I Have Heard Piano Concerto-Yellow River”.

\section{Trend Analysis of MTCSOL Dissertation Topics}

The trend of MTCSOL dissertations may be roughly divided into four stages according to their yearly features.

1. Stage 1 (2007-2008): At this stage, most MTCSOL dissertations were from specialties like linguistics and applied linguistics, curriculum and teaching methodology, centering on the research field of Chinese grammar. Taking Beijing Language and Culture University, the leader of MTCSOL, as an example, research focuses are function words and sentence patterns. In "Acquisition Process Investigation of Adverbs '才 (cai)' and ‘就 (jiu)' by Overseas Students”, Cao (2007) synchronically analyzed the characteristics and rules of “才 (cái)” and “就 (jiü)” by overseas students and put forward some suggestions on Chinese language teaching. In “A Comparative Study of Chinese '比 (bǐ , compare)' and English 'Than' Constructions”, taking an English version of Qian Zhongshu’s 围城 (wéi chéng, Besieged) as an example, Wang (2007) emphatically compared comparative sentences between Chinese and English. Based on studies of corpora, the author found that there are many similarities between the “比 (bǐ , compare)" construction in Chinese and the "than” construction in English, which can be used to help overseas students acquire the “比 (bǐ , compare)” construction. In addition, the author had also found that there are six differences between these two constructions, which should not be overlooked by the learners.

2. Stage 2 (2009-2011): Dissertations on TCSOL began to appear and have gradually become the dominant part of TCSOL researches in Chinese dissertations. Especially after full-time MTCSOL became available in 2009, dissertations on TCSOL have made a great leap forward. During this period, MTCSOL dissertations related to teaching methods for teaching Chinese as a foreign language have gradually increased, most of which are researches based on certain culture backgrounds and pay more attention to language contrast and negative transfer of mother tongue. Besides analyzing differences and similarities between two languages, these researches also studied overseas students' Chinese language problems resulted from their mother tongues, analyzed error causes, and proposed some teaching methods. In "Research and Practical Use on the Culture-Interpretation-Based-Model in the CAF-Class-Taking Germany as an Example”, based on the author's own Chinese teaching experience in Germany, Wang (2010) had made an in-depth analysis of Chinese learners' cognitive context, culture background, and national conditions in Germany (German-speaking regions) and explored innovation of teaching models in teaching Chinese as a foreign language.

3. Stage 3 (2012-2013): Dissertations became more specialized and were not confined within a certain module. Instead, they often combined one teaching method closely with actual teaching situations, teaching objects, or course categories, which made them belong to both teaching method researches and inter-cultural communication researches. In "Researches of Personal Pronoun Teaching Strategies for Italian Students - Contrast Study of Personal Pronouns Between Chinese and Italian”, Wang (2013) covered not only related contents of inter-cultural communication, but also various errors that learners might commit in acquiring Chinese as a second language, and explored teaching strategies of personal pronouns. Dissertation 
topics involved several modules and were more targeted in the teaching practice.

4. Stage 4 (2014-): At this stage, more and more researches are focused on culture and communication, cover not only researches on Chinese culture dissemination, but also related researches into traditions and cultures of learners' mother countries, and take full consideration of interactivity in language learning. In "Comparison and Analysis Between Calligraphy Textbooks Chinese Calligraphy and Amazing Characters \& Magic Brushwork on Teaching Chinese as a Foreign Language”, from the perspective of overseas students, beginning with goals, arrangements, teaching contents, exercises, and others of textbooks, Zheng (2014) comparatively studied these two relatively authoritative textbooks of Chinese calligraphy and offered some workable suggestions. In "Comparison Experiment of Chinese Indonesia Plants Proverb”, Huang (2015) has conducted ontological comparison of Chinese and Indonesian proverbs containing plant words, searched for factors causing differences between Chinese and Indonesian proverbs (different natural environment, social customs and habits, religious beliefs, value orientation, social structure, etc.) and proposed some corresponding strategies for teaching proverbs.

In addition, abundant multimedia resources have also provided new thoughts for MTCSOL dissertation topics, which has become the new trend in selecting dissertation topics in the last two years. Wang Mulin adapted one episode of the TV series "Traveling in China" with an attempt to insert some story-board interludes of the episode into the culture teaching classroom and achieved great results, providing many worthy references for designing classroom of teaching Chinese culture. The experiment and related researches eventually turn into the dissertation "Application of Film and Television Platform in the Teaching of Chinese Culture-Taking 'Traveling in China' as an Example” (2016).

In a word, MTCSOL dissertations (2007-2017) have showed a trend of extensive research scopes, specified research fields, individualized research objects, and diversified research methods. More and more researches of teaching methods, textbooks, the status quo of overseas TCSOL, and volunteers' mental health based on culture backgrounds and teaching practice have emerged.

\section{Reflection and Discussion}

Through the brief investigation of MTCSOL dissertation topics (2007-2017), it can be noticed that these topics have features of empirical researches stressing on teaching Chinese as a second language and adopting questionnaire survey, classroom observation, interviews, literature searching, and other methods. However, there still exist some problems which can be further discussed and investigated in future MTCSOL dissertations.

\section{Too Concentrated on Similar Topics}

Through study of the 50 sample dissertations and interpretation of the trend of dissertation topics in recent years, we find that both teaching Chinese as a second language and culture and communication have always been the most prioritized choices of MTCSOL dissertations. Topics concentrated on a few research focuses have been repeatedly studied. Research perspectives are often too single and research findings are too superficial, which have resulted in too concentrated and too simplified dissertation topics.

Among various causes for this phenomenon, the most primary one is students' weak consciousness of problems. In their practice, they are not observant of problems and do not have the sensitivity to problems. 
Thus, many dissertation topics are very much alike and their researches are quite similar to each other.

Meanwhile, there are very few dissertations about quality of Chinese language teachers. In contrast to the continuously rising "Chinese craze", there exists a relatively big gap between the actual supply and demand of TCSOL teachers both in quantity and quality. As the reserve force for TCSOL, MTCSOL students may, by combining the actual need of TCSOL with their professional training, consider the quality of Chinese language teachers as their dissertation topics.

\section{Lack of Creativity and Practicality}

TCSOL is a comprehensive specialty integrating linguistics, pedagogy, literature, and other disciplines together. We should be discreet and earnest in conducting related researches. In writing MTCSOL dissertations, students should keep a close watch on the frontiers of TCSOL-related researches and their topics should be on essential issues of TCSOL and have application values.

However, our investigation finds that a fair number of dissertation topics are of rigid forms and often cover too wide ranges. For instance, some dissertations discussed the prospects of TCSOL, but their contents lack constructiveness and the research results and suggestions are wanting in originality and feasibility.

Besides, MTCSOL gives priority to practical teaching skills and there should be higher demand of practical abilities for MTCSOL students. Of MTCSOL dissertations, quite a few are about teaching design for a class. However, to the exclusion of several quality ones, a lot of dissertations just made teaching designs based on some certain teaching theories and paid little attention to reflection upon TCSOL practice and lacked practicality. Only teaching designs developed with authentic investigation, observation, and numerous teaching practice can be truly practical and creative.

\section{Lack of Pioneering Spirit in Topic Selections}

“Guidelines of Dissertations for Master of Teaching Chinese to Speakers of Other Languages” released by the national guiding committee for MTCSOL requires students to pay close attention to the frontiers of TCSOL. However, most MTCSOL students did not attach enough importance to this. In comparison with other disciplines, MTCSOL, a specialty with a history of over a decade, is in want of mature training modes. In fact, some students lack necessary recognition of their specialty and have a poor knowledge about their curriculum and disciplinary development. They just mechanically and passively complete the study of their courses and seldom take any active action in the teaching practice or study the disciplinary trends and lack pioneering spirits. Almost no dissertations have involved language strategy, teacher development, curriculum studies, testing research and studies on special groups. Besides, there also exist various problems like insufficient data collection, less-targeted topics, and non-standard dissertation formats.

For the purpose of solving these problems, MTCSOL students should be encouraged to follow closely the trends of TCSOL with interest and combine theory with the teaching practice. In addition, MTCSOL supervisors should actively guide and encourage their students to study disciplinary theories and research methods, participate in TCSOL teaching themselves and conduct cutting-edge and creative researches. MTCSOL students should give their full support to the Belt and Road Initiative and build a harmonious community with shared future for humanity, take up the historic mission of international Chinese language teaching, broaden their horizons, have the world in their minds, and contribute to the promotion of TCSOL. 


\section{References}

Cao, X. (2013). Empirical research methods and quantitative data analysis for applied linguistics-from the perspective of TCSOL. Beijing: World Publishing Corporation.

Cao, Y. (2010). Teaching design of I have heard piano concerto-Yellow River (Unpublished master’s thesis, Jilin University).

Cao, J. (2007). Acquisition process investigation of adverbs “才 (cai)” and “就 (jiu)” by overseas students (Unpublished master’s thesis, Beijing Language and Culture University).

Huang, H. (2015). Comparison experiment of Chinese Indonesia plants proverb (Unpublished master’s thesis, Hebei Normal University).

Li, Q. (2009). The objectives and rationales of MTCSOL. Applied Linguistics, (3), 105-112.

Lv, T. (2007). Application of task design of TBLT to the primary stage of oral TCSL (Unpublished master's thesis, Beijing Language and Culture University).

Meng, P. (2012). Culture vocabulary in TCSOL and related teaching researches (Unpublished master's thesis, Shaanxi Normal University).

$\mathrm{Xu}, \mathrm{Q}$. (2008). Introduction of cultural knowledge in teaching Chinese as a foreign language (Unpublished master's thesis, Central China Normal University).

Wang, Z. (2009). Teacher talk in oral interaction in TCFL elementary classrooms: A survey and analysis (Unpublished master's thesis, Xiamen University).

Wang, Z. (2010). Research and practical use on the culture-interpretation-based-model in the CAF-class (Unpublished master's thesis, Zhejiang University).

Wang, F. (2007). A comparative study of Chinese “比 (bi)” and English “Than” constructions (Unpublished master’s thesis, Beijing Language and Culture University).

Wang, S. (2013). Researches of personal pronoun teaching strategies for Italian students—contrast study of personal pronouns between Chinese and Italian (Unpublished master's thesis, Liaoning Normal University).

Wang, M. (2016). Application of film and television platform in the teaching of Chinese culture (Unpublished master's thesis, Hunan Normal University).

Zhao, X. (July 19, 2017). 511 Confucius institutes overseas. People’s Daily (overseas edition).

Zheng, Z. (2014). Comparison and analysis between calligraphy textbooks Chinese calligraphy and amazing characters \& magic brushwork on teaching Chinese as a foreign language (Unpublished master's thesis, Sichuan Normal University). 